\title{
Original Study
}

Open Access

Paweł Siemaszko*, Zygmunt Meyer

\section{Analysis of the pile skin resistance formation}

https://doi.org/1010.2478/sgem-2021-0026

received March 3, 2021; accepted September 7, 2021.

\begin{abstract}
This paper introduces a method based on a static load test which is aimed to verify the mechanism of the piles soil-skin interaction. The authors base their analysis on detailed data from static load test with extensometers on CFA piles. The main goal of the research is to determine the proper method of examining how the skin of the pile and soil interacts and apply it to practical engineering practice. As the first stage of the research is limited to the available set of piles, the authors make assumptions that will be verified on later stages of research as more data become available. The authors attempt to formulate the boundary conditions for the formation of pile skin resistance formation using mathematical physics equations to describe the phenomena. Current research proves that it is possible, with the suitable for practical engineering calculations, to describe soil-pile interaction mechanism based on static load test results. Experimental research indicated that there is possibility, for practical engineering calculations purposes, to assume that skin resistance of the pile due to depth can be presented with linear graph. The description is made upon extensometer results, but is meant to be appropriate with the standard static load test results, which provide load-settlement curve of the pile.
\end{abstract}

Keywords: load-settlement; skin resistance; pile bearing capacity.

\section{Introduction}

The methods used to describe the relationship between load at the head and settlement of a pile have been analysed by many authors $[4,14,16]$. These works focus mostly on static load test results, which contain the set of load and corresponding settlement values obtained

\footnotetext{
*Corresponding author: Pawet Siemaszko, West Pomeranian Institute of Technology Szczecin, Faculty of Civil Engineering and Architecture, al. Piastów 50, 70-311 Szczecin, E-mail:

Zygmunt Meyer, West Pomeranian Institute of Technology Szczecin, Faculty of Civil Engineering and Architecture, al. Piastów 50, 70-311 Szczecin
}

during the test. These sets are presented as loadsettlement curves, which can be interpreted using various approaches $[3,15]$. The load-settlement curves may be used in a group of piles as well [7]. It has been argued that there is need for additional instrumentation during static load tests in order to obtain additional information about soil-pile interaction $[3,4]$.

Several papers combine field results and theoretical calculations of the dependency of shear stress distribution along the pile skin and settlement [19]. Others [8, 14, 17] focus on laboratory-based experiments. This allows for analysis in perfect soil environments, which do not appear in field cases. As such, calculations are more precise. However, works that employ the analytical approach, however, and in particular the soil mechanics theory, in particular, are scarce.

The main topic of this paper is the formation of shear stress along the skin of the pile due to soil-pile interaction. In a previous work [12], the authors proposed a definition of shear stress as the result of soil-pile interaction due to the bending of the space of soil around the pile, which is the result of the vertical movement of the pile. Kirchhoff's principle was used as a base for the description of the mentioned mechanism [11]. This theory forms the foundation of this paper. It is used to describe the formation of shear stress while loading a pile vertically with increasing force.

The authors' intention in this paper is to draw attention to the fact, that in each studied case there is a need to specify the boundary conditions, especially those of the skin of the pile. That is the main goal of this paper.

\section{Analysis}

The model that was analysed is a pile loaded vertically, whose movement is the result of the load put at the head. It is assumed that the cross-section of the pile is circular, and that $z$-axis, which is the vertical axis of the coordinate system, goes along the pile symmetry axis. The pile diameter is denoted as $D$, while pile length in the soil is denoted as $h$. The authors have analysed a concrete pile, which follows the assumption that the concrete is homogeneous and isotropic. 


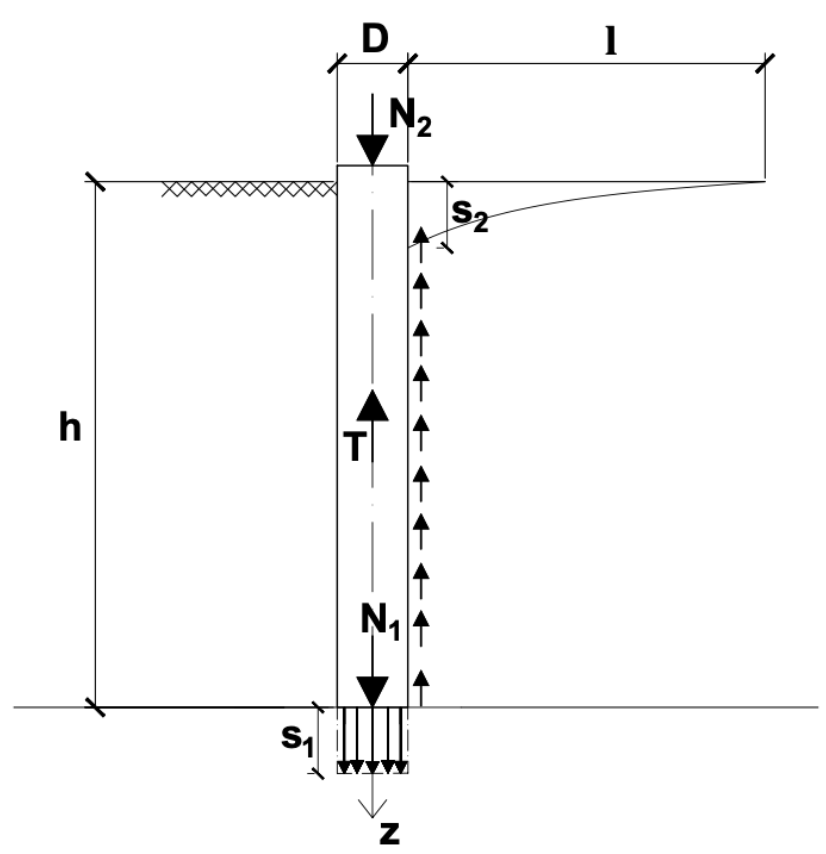

Figure 1: Loaded pile scheme.

Symbols on Figure 1:

$D$ - pile diameter [m]

$h$ - length of the pile in the soil [m]

l- arm of bending space [m]

$N_{1}$ - load at the base of the pile [MN]

$N_{2}$ - load at the head of the pile [MN]

$N(z)$ - axial force in the pile at $z$ depth [MN]

$\tau(z)$ - shear stress on the pile skin at $z$ depth [MPa]

$s$ - settlement value of the pile [mm]

$s(z)$ - settlement of the pile at $z$ depth [mm]

The equations describing the dependence of shear stress and movement of the pile at $z$ depth are based on Kirchhoff's principle as follows:

$$
s(z)=\frac{\tau(z) \cdot l}{G}
$$

where:

$$
G=\frac{E_{S, v}}{2(1+v)}
$$

It has been verified in experimental analysis [17] that the Equation (2) equation can be applied for practical calculations purposes for the linear part of $Q-S$ graph which can be up to $\frac{N}{N_{g r}}=0,5$.

For the interior of the pile, along the axis of symmetry, the load at the head changes its value as shown below:

$$
N(z)=N_{2}-\int_{0}^{z} \pi \cdot D \cdot \tau(z) \cdot d z
$$

In Eqs. (1) and (2), the following symbols are used: $E_{s, V^{-}}$ modulus of elasticity of soil in vertical direction near pile skin [MPa]; $v$ - Poisson coefficient of the soil.

Another equation describes the effect of the elastic shortening of a pile, which is due to vertical load. There is:

$$
s_{*}(z)=\frac{4}{\pi D^{2} E_{c}} \cdot \int_{0}^{z} N(z) d z \text { where: }
$$

in which: $\mathrm{s}_{x^{-}}$pile shortening value at $z$ depth $[\mathrm{mm}]$; $E_{c}$ - elasticity modulus of concrete [MPa].

Using the above introduced symbols, the relationship between vertical displacement, including the pile shortening effect and the shear stress on its skin is as follows:

$$
s(z)-s_{*}(z)=2(1+v) \cdot \frac{\tau(z) \cdot l}{E_{t}}
$$

It is assumed that pile displacement causes no additional skin slip between soil and pile skin.

The next assumption is that in Eq. (5), the following relationships are used:

$$
\begin{gathered}
\frac{d^{2} s(z)}{d z^{2}}=0 \text { and so } \\
s(z)=s_{2}-\left(s_{2}-s_{1}\right) \cdot \frac{z}{h}
\end{gathered}
$$

It is also assumed that for $N_{2}=0$ there is no shear stress on the skin of the pile that may be the result of technology used or the state of tension around the pile.

Under this assumption, combining Eqs. (5), (3) and (4), the following linear equation is obtained:

$$
\begin{aligned}
& \frac{d^{2} \tau}{d(a \cdot z)^{2}}-\tau=0 \text { where } \\
& a=\sqrt{\frac{2 \cdot E_{t}}{(1+v) \cdot E_{c} \cdot D \cdot l}}
\end{aligned}
$$

In general, if the requirement in Eq. (6) is not valid, there is shear stress although the pile is unloaded. As such, Eq. (8) is embodied as:

$$
\frac{d^{2} \tau}{d(a \cdot z)^{2}}-\tau=f(z) \text { where }
$$

$F(z)$ is a given function for additional boundary conditions. As mentioned above, this effect was neglected. The solution of the differential Eq. (8) is as follows:

$$
\tau(z)=A_{1} \cdot \sinh (a z)+A_{2} \cdot \cosh (a z)
$$


Boundary conditions for this equation are:

$$
\begin{gathered}
\text { For } z=0 \text { there is } \tau=\tau_{2} \\
\text { For } z=h \text { there is } \tau=\tau_{1} \\
A_{2}=\tau_{2} \\
A_{1}=\frac{\tau_{1}-\tau_{2} \cdot \cosh (a h)}{\sinh (a h)}
\end{gathered}
$$

Function $\tau(z)$ allows to calculate the load from Eq. (3) and the pile shortening from Eq. (4).

After implementation of Eqs. (13) and (14), it follows that:

$$
\tau(z)=\frac{\tau_{1}-\tau_{2} \cdot \cosh (a h)}{\sinh (a h)} \cdot \sinh (a z)+\tau_{2} \cdot \cosh (a z)
$$

A detailed analysis of constant " $a$ " suggests that, in practical engineering, its value is very small; therefore, $\mathrm{a} \bullet \mathrm{h} \ll<1$ which takes into consideration the asymptotic solution:

$$
\lim _{a \rightarrow 0}(\tau, a)=\tau(z)=\tau_{2}-\left(\tau_{2}-\tau_{1}\right) \cdot \frac{z}{h}
$$

Eq. (17) provides another relationship that includes loads at the head $N_{2}$ and base $N_{1}$ of the pile:

$$
\begin{gathered}
\frac{N_{2}-N_{1}}{\pi D h}=\frac{\tau_{2}+\tau_{1}}{2} \text { and so } \\
N(z)=N_{2}-\pi D h \cdot\left[\tau_{2} \cdot\left(\frac{Z}{h}\right)-\frac{1}{2}\left(\tau_{2}-\tau_{1}\right) \cdot\left(\frac{z}{h}\right)^{2}\right]
\end{gathered}
$$

The above equation was applied for the estimation of $\tau_{2}$ based upon field measurements.

Field tests were conducted on real piles. The method of static load test provided sets of data $\{N ; s\}$ for different load stages. Independently, with the use of extensometers, the vertical axial force available for different stages of external load was distributed at the head of the pile $N_{2}$. The equation used for the approximation for reference $N_{2}$ is as follows:

$$
N\left(z_{i}\right)=N_{2}-\pi D h\left[\tau_{2} \cdot\left(\frac{z_{i}}{h}\right)-\left(\tau_{2}-\frac{N_{2}-N_{1}}{\pi D h}\right) \cdot\left(\frac{z_{i}}{h}\right)^{2}\right]
$$

which includes:

$$
\tau_{1}=\frac{N_{2}-N_{1}}{\pi D h} \cdot 2-\tau_{2}
$$

The value of $\tau_{2}$ in Eq. (21) was calculated using Eq. (20) for a given load at the head of the pile and the forces obtained along the pile axis. The least squares method was used for the calculations, which can be presented as:

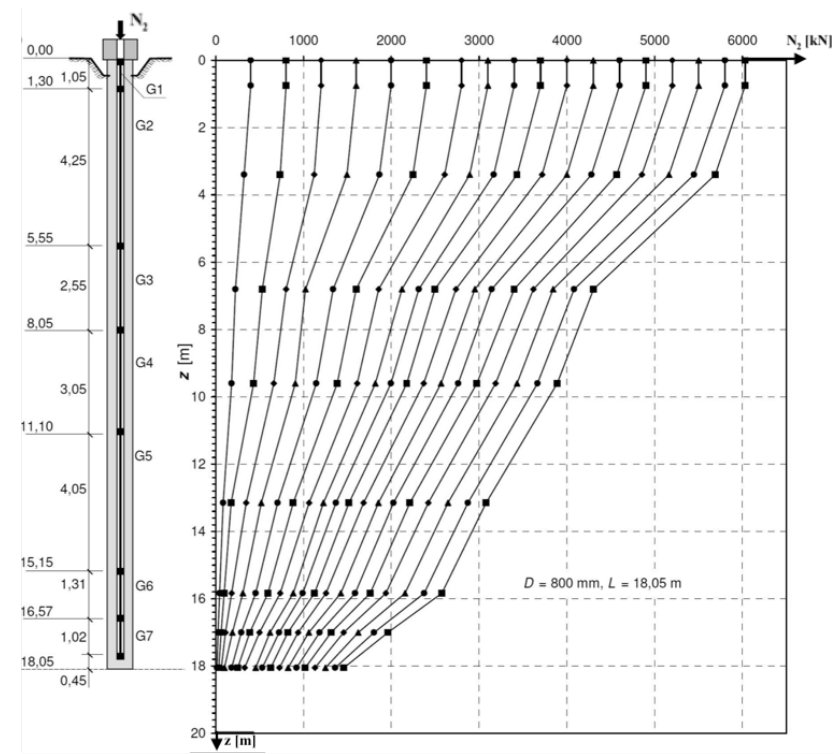

Figure 2: Placement of strain gauges for Pile 1, forces graph [9].

$$
\delta^{2}=\sum\left[N_{i}-N\left(z_{i} ; \tau_{2}\right)\right]^{2}=\min
$$

in which: $N_{i}$ - pile skin force measured at " $z_{i}$ " depth; $N\left(z_{i}\right)$ - load calculated using Eq. (20).

The main aim of the proposed method was to check if the least squares method with Eq. (22) led to normal squared differences distribution. This would prove that the simplification given by Eqs. (7) and (17) can be applied.

\section{Field investigation}

Two piles were fully analysed. Their dimensions are: diameter $\mathrm{D}=0.8 \mathrm{~m}$, length $\mathrm{L}=18.05 \mathrm{~m}$. The piles were drilled using the CFA method. They were used as foundations for overpasses in Gdańsk on the Wysoczyzna Kaszubska territory. The soil was a mix of cohesive and non-cohesive layers.

The most important results were shear stress values. In order to measure them, one approach is to place the steel tube with the extensometers along the pile shaft. The system of extensometers was an addition to the static load test. The obtained results allowed the authors to compare the theoretical analyses they were working on, with actual results from the piles used as a functioning foundation.

Fig. 2 presents the results of a set of extensometers for one of the analysed piles:

The tables below show the main data obtained from the static load test of Pile 1 and Pile 2. 

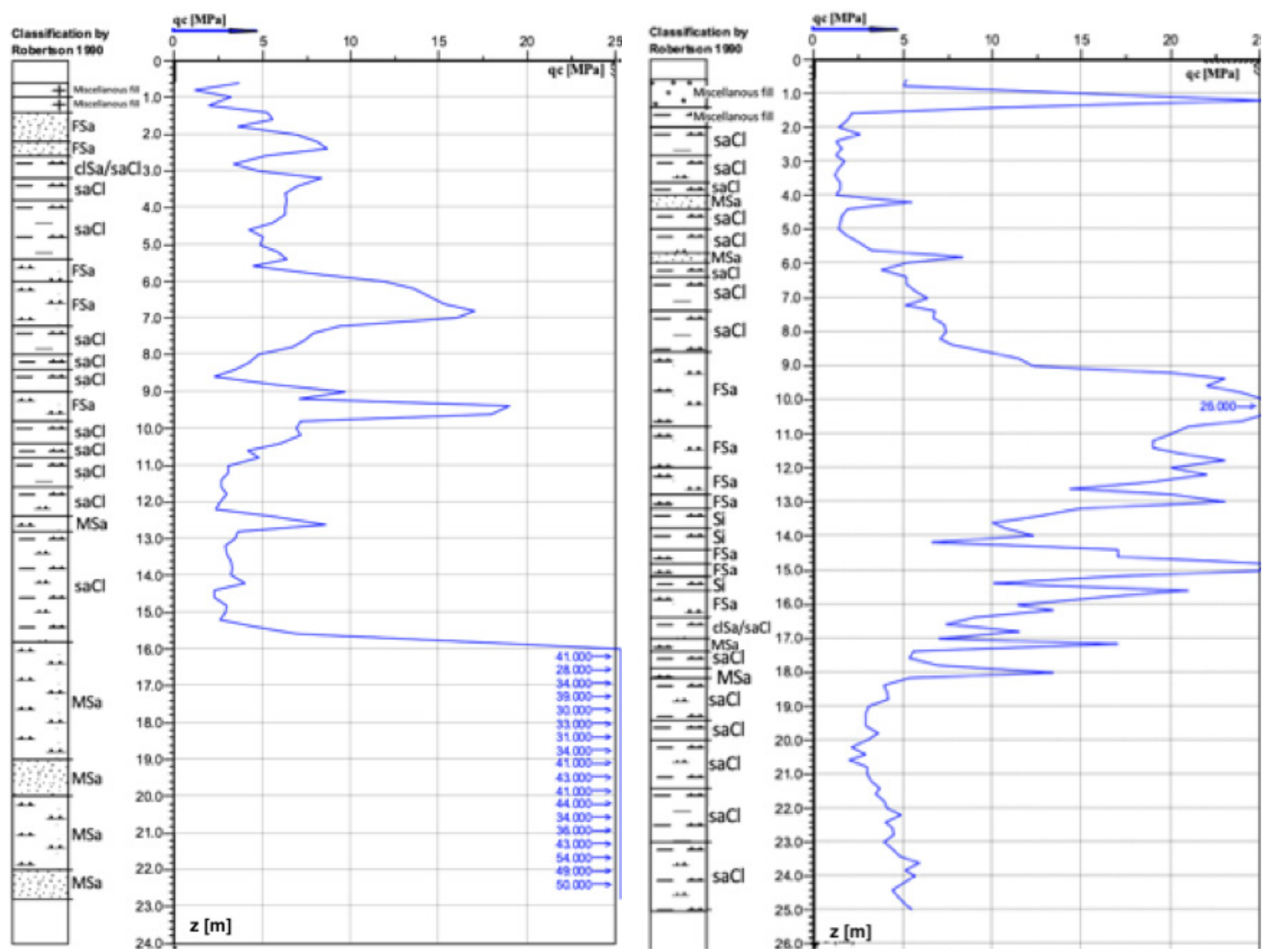

Figure 3: Graph of CPTu investigation results for Pile 1 (left graph) and Pile 2 (right graph) [9].

Table 1: Static load test values for Pile 1.

\begin{tabular}{|c|c|c|c|}
\hline \multirow{18}{*}{ 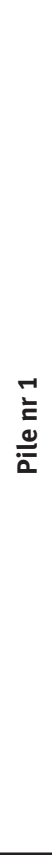 } & Dimensions & $\mathrm{N}_{2}[\mathrm{kN}]$ & $\mathrm{s}_{2}[\mathrm{~mm}]$ \\
\hline & $\mathrm{D}=0,8 \mathrm{~m}$ & 6100 & 14,05 \\
\hline & & 5800 & 12,29 \\
\hline & & 5500 & 10,42 \\
\hline & $\mathrm{H}=18,05 \mathrm{~m}$ & 5200 & 9,42 \\
\hline & & 4900 & 8,28 \\
\hline & & 4600 & 7,21 \\
\hline & & 4300 & 6,36 \\
\hline & Technology: CFA & 4000 & 5,64 \\
\hline & & 3700 & 4,75 \\
\hline & & 3400 & 4,23 \\
\hline & & 3100 & 3,56 \\
\hline & & 2800 & 2,83 \\
\hline & & 2400 & 2,24 \\
\hline & & 2000 & 1,76 \\
\hline & & 1600 & 1,27 \\
\hline & & 1200 & 1,12 \\
\hline & & 800 & 0,74 \\
\hline
\end{tabular}

Table 2: Static load test values for Pile.

\begin{tabular}{|c|c|c|c|}
\hline \multirow{17}{*}{ 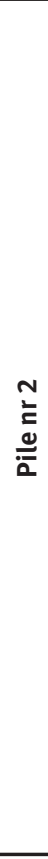 } & Dimensions & $\mathrm{N}_{2}[\mathrm{kN}]$ & $\mathrm{s}_{2}[\mathrm{~mm}]$ \\
\hline & $\mathrm{D}=0,8 \mathrm{~m}$ & 4800 & 25,46 \\
\hline & & 4500 & 18,23 \\
\hline & & 4200 & 13,28 \\
\hline & $\mathrm{H}=18,05 \mathrm{~m}$ & 3900 & 8,85 \\
\hline & & 3600 & 6,83 \\
\hline & & 3300 & 5,48 \\
\hline & & 3000 & 4,42 \\
\hline & Technology: CFA & 2700 & 3,6 \\
\hline & & 2400 & 2,89 \\
\hline & & 2100 & 2,27 \\
\hline & & 1800 & 1,69 \\
\hline & & 1500 & 1,28 \\
\hline & & 1200 & 0,98 \\
\hline & & 900 & 0,7 \\
\hline & & 600 & 0,43 \\
\hline & & 300 & 0,2 \\
\hline
\end{tabular}




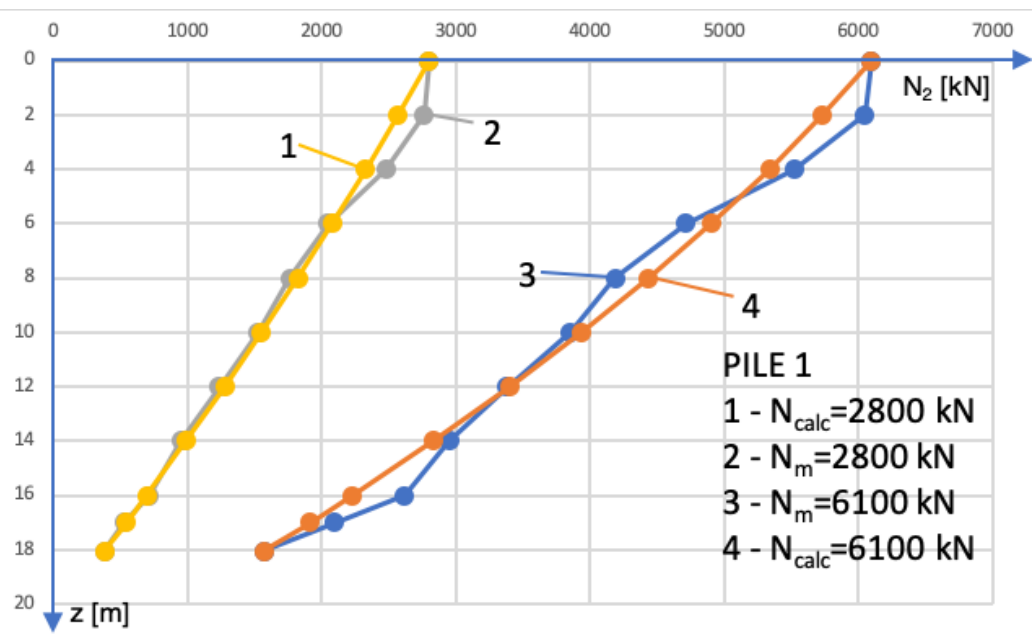

Figure 4: Comparison of values obtained from measurements (m index) with authors' calculations (calc index) for Pile 1, different loads.

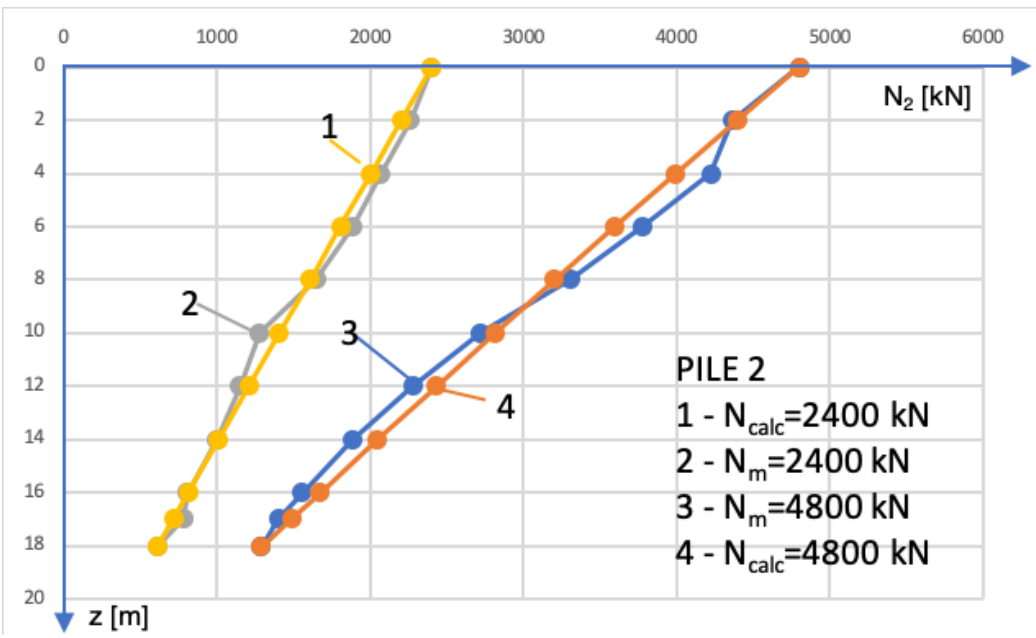

Figure 5: Comparison of values obtained from measurements ( $m$ index) with authors' calculations (calc index) for Pile 2, different loads.

For these piles, as mentioned above, we obtained the CPTu soil investigation results. The graphs are presented in Fig. 3.

The first step of the calculations was to determine if the " $a$ " parameter should be implemented or neglected. Then, the shear stress graph was optimised based on the " $a$ " value. The authors tried to obtain the most probable, and closest to the experiment, graph of shear stress value. Upon this step, calculations were made using the least squares methods. In this way, the " $a$ " parameter value was optimised. It can be proved that parameter " $a$ ", specified by Eq. (9), is a very small value in comparison to the width and length values of the pile. Assuming average conditions $E_{s, v}=10 \mathrm{MPa}, v=0,25, E_{c o n}=30 \mathrm{GPa}, D=0,8 \mathrm{~m}, l \cong 3 \mathrm{D}$, the value of $a=0,016[1 / \mathrm{m}]$.
Upon calculations for different piles, it was concluded that, for practical purposes, the influence of " $a$ " can be neglected.

The next step was to compare the theoretical calculations of pile loads with the corresponding experimental results. Using the method shown above, for each pile, calculations of shear stress were made.

Once the set of data was obtained, a comparison was made between theoretical and experimental results. For each pile, there was normal distribution of squared differences, which proves the assumption that $\frac{d^{2} s}{d z^{2}}=0$. In Figs. 4 and 5, we compare the theoretical and experimental values $N(z)$.

The same comparison for Pile 2 is shown in Fig. 5. 


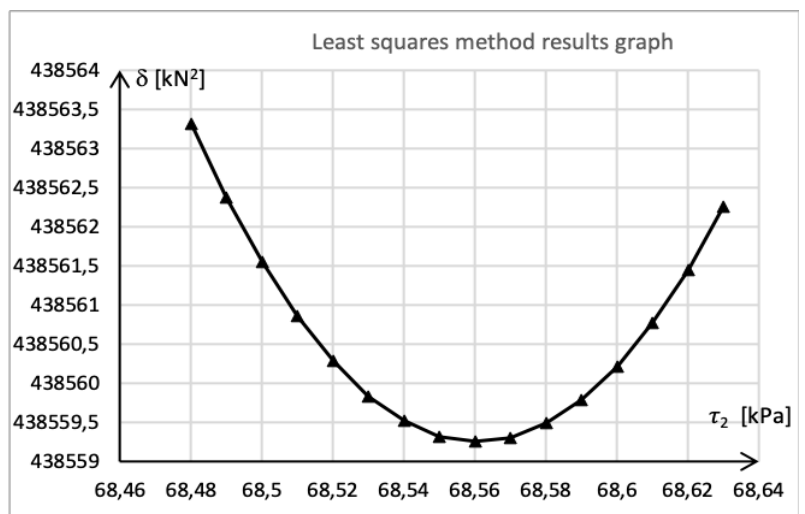

Figure 6a: Least squares method for Pile $1 N_{2}=6100 \mathrm{kN}$.

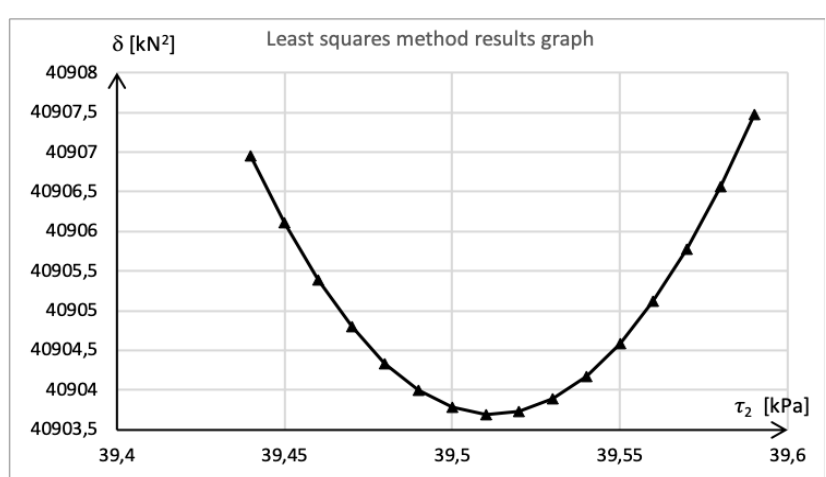

Figure 6b: Least squares method for Pile $2 N_{2}=2400 \mathrm{kN}$.

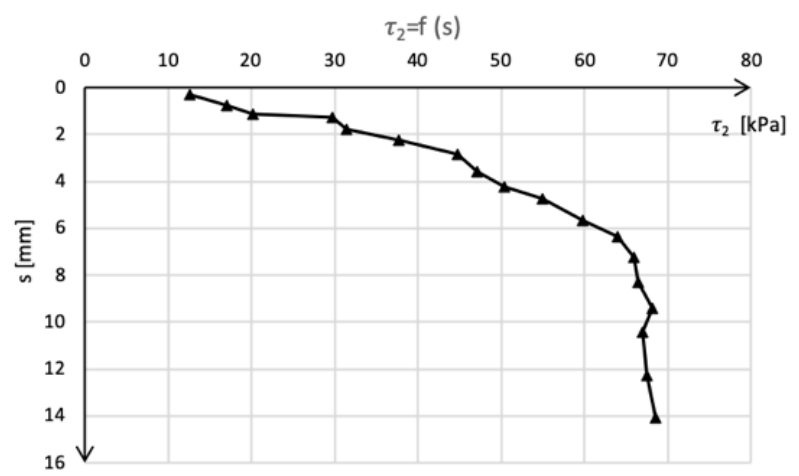

Figure 7a: Relationship between settlement and shear stress at the head of Pile 1.

In Figs. $6 \mathrm{a}$ and $6 \mathrm{~b}$ we show an example of a normal distribution graph obtained with the least squares method for both analysed piles.

The least squares methods, as shown in Eq. (20), allows to optimise the value of shear stress along the skin of the pile. Examples are shown in Figs. 7a, 7b, 8a, and 8b.

At this stage, conclusions can be formulated based upon the experiments:

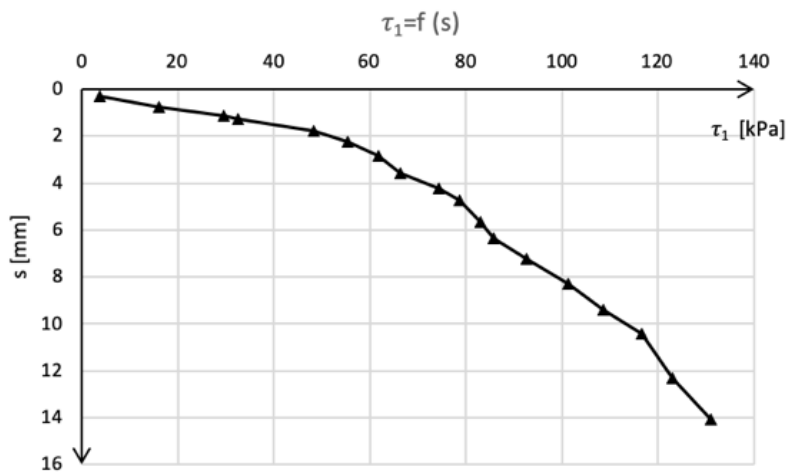

Figure 7b: Relationship between settlement and shear stress at the base of Pile 1.

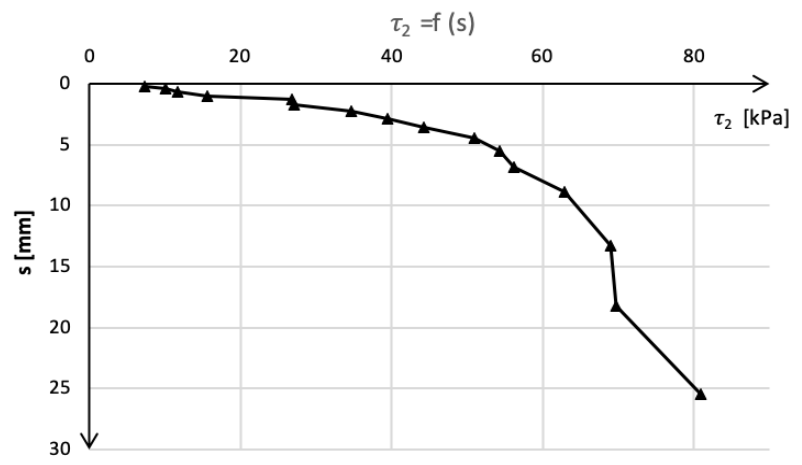

Figure 8a: Relationship between settlement and shear stress at the head of Pile 2.

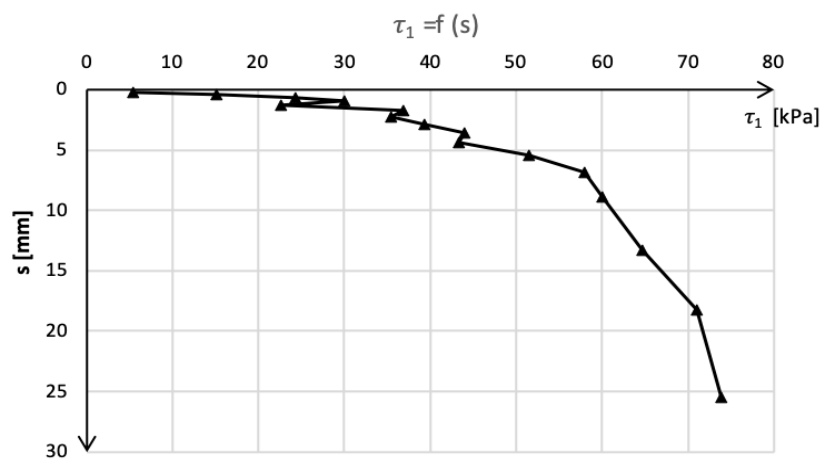

Figure 8b: Relationship between settlement and shear stress at the base of Pile 2 .

1. The experimental results prove that for practical calculations, the following simplification can be applied: $-\frac{d^{2} s}{d z^{2}}=0$; and $a \rightarrow 0$, moreover

2. The following equations can be used for the practical estimation of the skin shear stress $\tau(z)$ and pile axis for $N(z)$ :

$$
\begin{aligned}
& -\tau(z)=\tau_{2}-\left(\tau_{2}-\tau_{1}\right) \cdot \frac{z}{h} \\
& -N(z)=N_{2}-\pi D h \cdot\left[\tau_{2} \cdot \frac{z}{h}-\left(\tau_{2}-\frac{N_{2}-N_{1}}{\pi D h}\right) \cdot\left(\frac{z}{h}\right)^{2}\right]
\end{aligned}
$$




\section{Analysis of the Experimental Results}

For a practical approach to combining field investigation data with theoretical calculations, it is essential to estimate value $\tau_{2}$ using soil investigations and static load tests without the need for extensometers. Kirchhoff's approach can be used for the analysis of soil reaction on pile settlement, Eqs. (1) and (2). This gives the following relationship:

$$
\tau_{2}=\frac{E_{s, v}}{2 \cdot(1+v) \cdot l} \cdot s_{2}
$$

In field investigations for each external load, settlement $s_{2}$ was measured and $\tau_{2}$ calculated, which allows to estimate (23). The following relationships are now available:

$$
\begin{gathered}
\tau_{2}=B_{2} \cdot s_{2} \\
B_{2}=\frac{E_{s, v}}{2 \cdot(1+v) \cdot l}
\end{gathered}
$$

In order to obtain $\tau_{2}$ stress values, the $\mathrm{M}-\mathrm{K}$ method [11] can be used with the static load test results. This method has been described above. The relationships are as follows:

$$
\begin{gathered}
s_{2}=\frac{\tau_{2} \cdot l}{E_{s, v}} \cdot 2(1+v) \\
s_{2}=C_{2} N_{g r 2} \cdot \frac{\left(1-\frac{N_{2}}{N_{g r 2}}\right)^{-\kappa_{2}}-1}{\kappa_{2}}
\end{gathered}
$$

In these equations: $C_{2}$ - aggregated Winkler modulus is introduced in [12]; $N_{g r 2}$ - limits pile bearing capacity [MN]; $\kappa_{2}$ - non-dimensional parameter, which represents the relation between pile skin and base resistance.

The above parameters may be obtained using statistical methods and the static load test results available as $\{N ; z\}$. For further analysis, it is convenient to consider the following $\mathrm{M}-\mathrm{K}$ method outcome:

For $\frac{\mathrm{N}_{2}}{\mathrm{Ngr}_{2}}<0,5$ simplified expressions can be used:

$$
\begin{gathered}
s_{2}=C_{2} \cdot N_{2} \text { and so } \\
\tau_{2}=C_{2} \cdot N_{2} \cdot B_{2} \text { and furthermore } \\
E_{s, v}=4 q_{c} \cdot\left(1+\frac{1}{4} q_{c}^{\frac{1}{3}}\right)[12] \text { and for practical calculations } \\
\mathrm{l} \cong 3 \mathrm{D}[17]
\end{gathered}
$$

As a result of the field investigations and the static load test, there is a set of data $\left\{N_{i} ; s_{i}\right\}$ for each pile obtained, and the following parameters are obtained with the statistical method: $C_{2}, \kappa_{2}, N_{g r 2}[13]$. These give the relation $N_{2}=N_{2}\left(s_{2}\right)$, as well as the corresponding set of $\left\{\tau_{2} ; N_{2}\right\}$. With this approach, we can calculate coefficient $B_{2}$ and so $\tau_{2}\left(N_{2}\right)$ can be compared with relevant $\tau_{2}\left(s_{2}\right)$.

The last value which remains to be calculated is $\tau_{1}$, namely, shear stress at the depth of the pile base, which is a reaction on $\tau_{2}\left(N_{2}\right)$ pile settlement. As above, $\tau_{1}$ is obtained with (21).

$$
\tau_{1}=\frac{N_{2}\left(s_{2}\right)-N_{1}\left(s_{2}\right)}{\pi D h} \cdot 2-\tau_{2}\left(s_{2}\right)=\tau_{1}\left(s_{2}\right)
$$

With the application of the previous relationships and the $\mathrm{M}-\mathrm{K}$ method parameters $[13,14,17]$, the following relation is obtained:

$$
\tau_{1}=N_{2} \cdot\left\{\frac{2}{\pi d H} \cdot\left(1-\frac{N_{1}}{N_{2}}\right)-B_{2} \cdot C_{2}\right\}
$$

The final version of Eq. (32) with M-K method relationships [17] applied, is as follows:

$$
\tau_{1}=N_{2} \cdot\left\{\frac{2}{\pi d H} \cdot \frac{\kappa_{2} \cdot\left(2+\kappa_{2}\right)}{\left(1+\kappa_{2}\right)^{2}}-B_{2} \cdot C_{2}\right\}
$$

For simplification, the authors described the previous equation as:

$$
\tau_{1}=N_{2} \cdot B_{1} \text { where } B_{1}=\frac{2}{\pi d H} \cdot \frac{\kappa_{2} \cdot\left(2+\kappa_{2}\right)}{\left(1+\kappa_{2}\right)^{2}}-B_{2} \cdot C_{2}
$$

Figs. $9 \mathrm{a}$ and $9 \mathrm{~b}$ show the linear distribution $\left\{\tau_{2} ; N_{2}\right\}$ obtained using Eqs. (25), (29), (30). $C_{2}$ values were optimised using the least squares method. Figs. 10a and 10b show the linear distribution for $\left\{\tau_{1} ; N_{2}\right\}$ obtained with Eq. (34).

\section{Conclusions}

1. This paper contains an interpretation of static load test results generated with extensometers to obtain the distribution of axial force along the pile shaft. The analytical part of this paper concerns a theoretical description of the mechanism of skin resistance formulation of the pile using Kirchhoff's approach by introducing the aggregate Winkler constant [12]. Two basic assumptions were made at that stage: the second derivative of settlement against depth and the actual value of $a$, which is very small for practical purposes, can be neglected. Both were confirmed in experimental research by obtaining the normal square difference distribution of data. The analysis of the experimental results was extended by using earlier research and incorporating the $\mathrm{M}-\mathrm{K}$ method for calculating $\tau_{1}, \tau_{2}$ shear stress. 


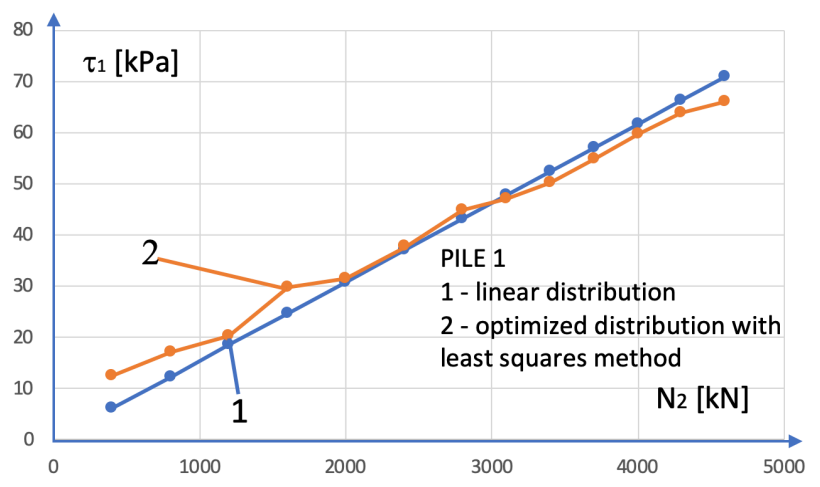

Figure 9a: Pile 1 values comparison; linear distribution for $B_{2}=5,28$.

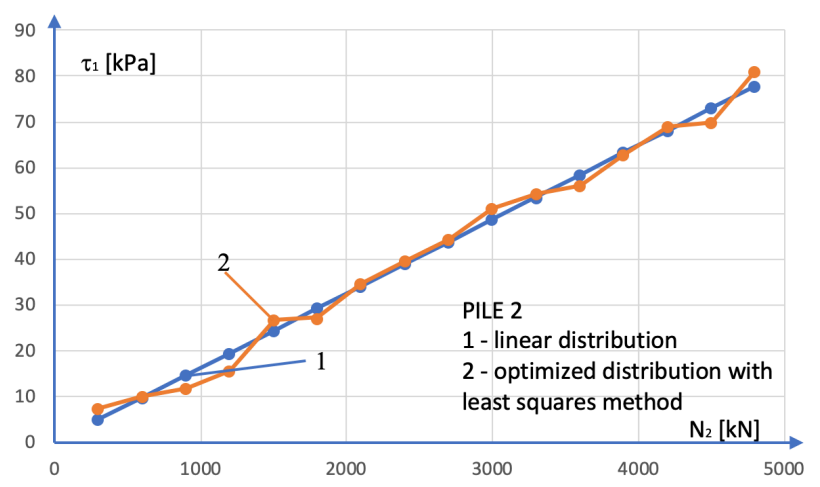

Figure 9b: Pile 2 values comparison; linear distribution for $B_{2}=6,89$.

2. The experimentally obtained values were compared to theoretical graphs. In these, pile shaft resistance at the head and base of the pile are crucial.

3. The analytical relationships were obtained on the basis of [12] and the $\mathrm{M}-\mathrm{K}$ parameters. It was found that the $\mathrm{M}-\mathrm{K}$ curve parameters obtained from pile static load test results, as well as soil investigations with the $\mathrm{CPTu}$ method, match the values obtained by calculations in which tension values $\tau_{1}$ and $\tau_{2}$ were the starting points of consideration. This allows the assumption that the solution shown in this paper is based on skin resistance and the corresponding settlement, and may be used for practical engineering calculations. Kirchhoff's method is applied and the skin resistance arises as the result of soil displacement around the pile. The authors aim to use the experimental results further, along with other studies in the literature and more field investigation experiments in various circumstances in order to verify the proposed method. The obtained results presented in graphs and tables are showing the accuracy of obtained values measured in experimental methods. The curves show that not all the cases agree fully with the linear theoretical

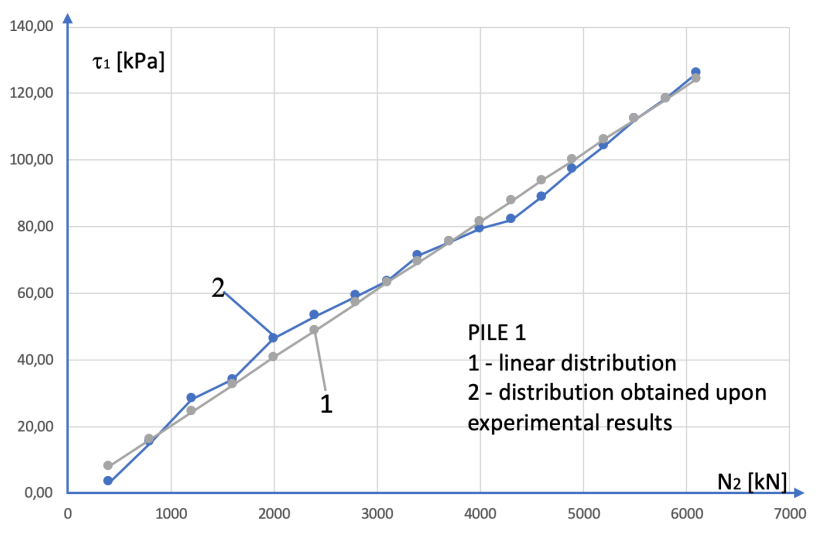

Figure 10a: Pile 1 values comparison; linear distribution for $B_{1}=0,02$.

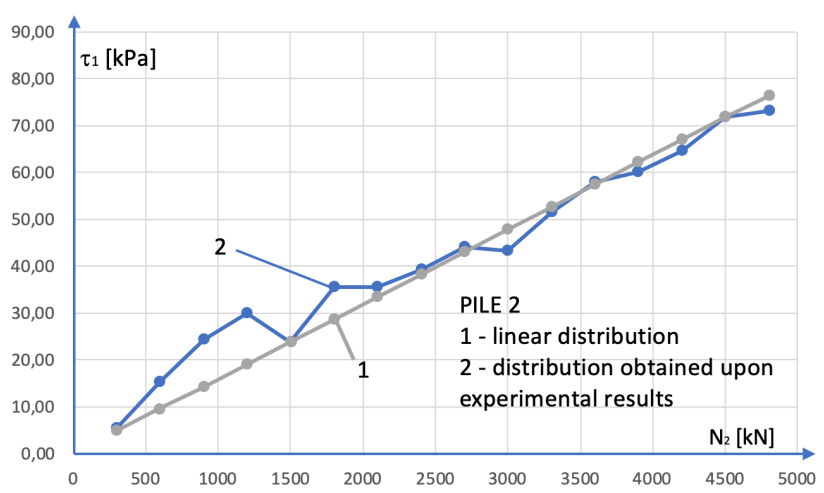

Figure 10b: Pile 2 values comparison; linear distribution for $B_{1}=0,01$.

assumption. However, there are cases that can be discussed to explain the inaccuracies.

4. The proposed method of calculating skin shear stress includes a parameter, which represents the behaviour of pile settlement in real soil conditions. The $\mathrm{M}-\mathrm{K}$ method is used for describing a set of $\left\{N_{i} ; s_{i}\right\}$ from static load test results, with the parameter in a way averaging soil conditions. Fig. 7a shows that when $N_{2}$ reaches a certain value, the resulting $\tau_{2}$ tends to be constant. The experimental results suggest that that $\tau_{2}\left(N_{2}\right)$ reached its maximum value. The maximum value of $\tau_{2}$ corresponds to the possibility of overcoming the static friction conditions of the pile against the soil. How to reach maximum shear skin resistance has been presented before by other authors $[1,3,4]$.

5. The authors would like to underline that to solve the problem of pile-soil interaction it is necessary to outline the mechanism of skin resistance formation. In this area there are no commonly accepted models of interaction as well as numerical solution that would expose the boundary conditions solved in the way accepted in solving differential equation according to 
Dirichlett. The authors' main intention is to formulate the boundary condition correctly, because the numerical solution can be improved using it as the input.

\section{References}

[1] Briaud J.L. (2013). Geotechnical engineering: unsaturated and saturated soils, Wiley, New Jersey. p. 575.

[2] Dunnicliff J.(1988). Geotechnical instrumentation for monitoring field performance. Wiley. Washington.

[3] Fellenius B.H. (2001) From strain measurements to load in an instrumented pile. Geotechnical News Magazine, Vol. 19, No. 1, pp. 35-38.

[4] Fellenius B.H. (2002). Determining the true distributions of load in instrumented piles. ASCE International Deep Foundation Congress “Down to Earth Technology”. Orlando, Florida.

[5] Fellenius B.H. (2006) Results from long-term measurement in piles of drag load and downdrag, Canadian Geotechnical Journal, Vol. 43, No. 4, pp. 409-430.

[6] Fellenius B.H., Kim S.R., Chung S.G. (2009) Long-term monitoring of strain in instrumented piles, ASCE Journal of Geotechnical and Geoenvironmental Engineering, Vol. 135, No. 11, pp. 1583-1595.

[7] Kacprzak G. M. (2018) Wspótpraca fundamentu płytowopalowego z podłożem gruntowym, Oficyna Wydawnicza Politechniki Warszawskiej, Warszawa

[8] Krasiński A., Kusio T. (2015). Pile model tests using strain gauge technology. Studia Geotechnica et Mechanica. Vol. 37, No. 3 .

[9] Krasiński A., Sikora Z., Kusio T. (2013) Scientific report of pile bearing capacity prepared for Keller Sp. Z o. o., Gdańsk

[10] Krasiński A., Wiszniewski M. (2017). Static load test on instrumented pile - field data and numerical simulations. Studia Geotechnica et Mechanica, Vol. 39, No. 3.

[11] Meyer Z., Kowalów M. (2010) Model krzywej aproksymującej wyniki testów statycznych pali, Inżynieria Morska i Geotechnika, Vol. 3. pp. 438-441.

[12] Meyer Z., Siemaszko P. (2019) Static load test analysis based on soil field investigations, Bulletin of the Polish Academy of Sciences Technical Sciences, Vol. 67, No. 2. pp. 329-337.

[13] Meyer Z., Stachecki K. (2018) Static load test curve (Q-s) conversion in to pile of different size. Ann. Warsaw Univ. Life Sci. - SGGW, Vol. 50. pp. 171-182.

[14] Meyer Z., Żarkiewicz K. (2018). Skin and toe resistance mobilisation of pile during laboratory static load test, Studia Geotechnica et Mechanica, Vol. 40. pp.1-5.

[15] Thilakasiri H.S.(2007). Qualitative interpretation of loadsettlement curves of bored piles. Engineer, Vol. 40, No. 4. pp. 61-68.

[16] Wrana B. (2015). Pile load capacity - calculations methods. Studia Geotechnica et Mechanica. Vol. 37, No. 4.

[17] Żarkiewicz K., PhD. (2017) Analysis of pile shaft bearing capacity formation in non-cohesive soils based on laboratory model investigation, West Pomeranian University of Technology in Szczecin, Szczecin. 